Çukurova Üniversitesi Mühendislik Mimarlık Fakültesi Dergisi, 33(1), ss. 87-96, Mart 2018

Çukurova University Journal of the Faculty of Engineering and Architecture, 33(1), pp. 87-96, March 2018

\title{
Kuru Tip Transformatör Optimizasyonuna Yeni Bir Yaklaşım: Ateş Böceği Algoritması
}

\author{
Tuğçe DEMİRDELEN*1 \\ ${ }^{1}$ Adana Bilim ve Teknoloji Üniversitesi, Mühendislik Fakültesi, Elektrik-Elektronik \\ Mühendisliği Bölümü, Adana
}

Geliş tarihi: 29.01.2018

Kabul tarihi: 14.03 .2018

\section{$\ddot{\mathbf{O z}}$}

Kuru tip transformatörler, ticari ve endüstriyel uygulamalarda oldukça popülerdir. Bu çalışmada Ateş böceği algoritması yöntemi kullanılarak kuru tip transformatörün yeniden tasarlanması yapılırken ağırlığının ve maliyetinin optimum seviyeye düşürülmesi amaçlanmıştır. Yapılan çalışma sonucunda transformatörün veriminin maksimum seviyeye çıkarılabileceği görülmüştür. Uygulama için $100 \mathrm{kVA}$ 'lık üç fazlı, kuru, çekirdek tipi nüveli transformatör kullanılmış olup öncelikle matematiksel modeli çıkarılıp daha sonra transformatör değişkenleri olan akım yoğunluğu (s) ve demir kesiti uygunluk faktörü (C) optimize edilerek ağırlık ve maliyet optimum seviyeye çekilmiştir. Performans analizi ayrıntılı şekilde yapılarak uygulanan optimizasyon yönteminin faydası en açık şekilde ortaya konmuştur.

Anahtar Kelimeler: Ateş böceği algoritması, Kuru tip transformatör, Optimizasyon, Verimlilik

\section{A New Approach to Dry Type Transformer Optimization: Firefly Algorithm}

\begin{abstract}
Dry type transformers are very popular in commercial and industrial applications. In this study, it is aimed to reduce the weight and cost to the optimum level while redesigning the dry type transformer by using the Firefly algorithm method. It can be shown that, the efficiency of the transformer can be increased to the maximum level by this work. For the application, A $100 \mathrm{kVA}$ three phase, dry, core type core transformer is used and fistly the mathematical model is obtained and then the weight and cost are optimized to adjust the current density (s) and the iron section compatibility factor (C). The benefit of optimizing the performance analysis is clearly demonstrated in detail.
\end{abstract}

Keywords: Firefly algorithm, Dry type transformer, Optimization, Efficiency

*Sorumlu yazar (Corresponding author): Tuğçe DEMIRDELEN, tdemirdelen@adanabtu.edu.tr 


\section{GíRiş}

Elektrik enerjisinin üretildiği santraller, üretimde kullanılacak hammadde kaynağı nedeniyle tüketim merkezlerinden ve kırsal kesimlerden uzak yerlerde kurulmaktadır. Üretilen elektrik enerjisini verimli bir şekilde iletebilmek için gerilim seviyesi yükseltilmektedir. Elektrik enerjisi tüketileceği yere iletildikten sonra, elektrik dağıtım merkezlerinde gerilimin düşürülmesi gereklidir. Elektrik enerjisini sabit güç ve sabit frekansta, gerilim seviyesini yükseltip/alçaltarak iletmede güç transformatörü denilen özel tip elektrik makineleri kullanılmaktadır. Elektrik enerjisinin iletim ve dağıtımında çok önemli bir yere sahip olan güç transformatörleri farklı özelliklere göre (gerilim seviyesi, anma gücü, izolasyon malzemesi vb.) sınıflandırılabilir.

Güç transformatörleri sargılar arası yalıtımı sağlayan izolasyon malzemesine göre; yağlı tip ve kuru tip transformatörler olarak ikiye ayrılır. Kuru tip transformatörler; yağlı tip transformatörlere göre patlayıcı olmayan, kendi kendine sönebilen, güvenli yapılarıyla daha avantajlıdır. $\mathrm{Bu}$ avantajları sayesinde, sanayide, iç mekan ve yeraltı tesislerinde, hastanelerde ve konut binalarında kullanilırlar [1-2].

Güç transformatörleri manyetik devredeki alçak gerilim (AG) ve yüksek gerilim (YG) sargıları ile manyetik bağlanma prensibine göre çalışır. AG ve YG sargıları üç fazlı transformatör nüvesinin aynı bacağında üst üste sarılır. Bu nedenle, $A G$ ve YG sargiları birbirinden yalitılmalıdır. Transformatörlerde sargılar arasındaki izolasyon yağ veya başka izolasyon malzemeleri ile sağlanmaktadır. Üç fazlı transformatörlerin uygun çalışması için AG ve YG sargılarının izolasyonu çok önemlidir. Eğer transformatörde bir yalıtım sorunu ortaya çıarsa, bu kısmi deşarj oluşmasına sebep olabilir.

$\mathrm{Bu}$ çalışmada ateş böceği algoritması yöntemi kullanılarak kuru tip transformatörün maksimum verim elde edilecek şekilde yeniden tasarımı yapılırken ağırlı̆ı̆ının ve maliyetinin optimum seviyeye düşürülmesi amaçlanmıştır. Yapılan çalışma sonucunda transformatörün ağırlığının ve maliyetinin optimum şekilde elde edilebileceği görülmüştür. Uygulama için 100 kVA'lık üç fazlı, kuru, çekirdek tipi nüveli transformatör kullanılmış olup öncelikle matematiksel modeli çıkarılıp daha sonra transformatör değişkenleri olan akım yoğunluğu (s) ve demir kesiti uygunluk faktörü (C) optimize edilerek ağırlık ve maliyet optimum seviyeye çekilmiştir. Performans analizi ayrıntılı şekilde yapılarak uygulanan optimizasyon yönteminin faydası en açık şekilde ortaya konmuştur.

\section{2. ÖNCEKİ ÇALIŞMALAR}

Literatürde kuru tip transformatörlerde [1-13] genetik algoritma, tabu arama algoritması, yerçekimsel arama algoritması kullanılarak optimizasyon çalışmaları ağırlık optimizasyonu [5], şekil optimizasyonu [6-7], maliyet optimizasyonu [3], verimlilik optimizasyonu [8], performans optimizasyonu [9-12] ve hata algilama çalışmaları [13] yapılmıştır. $\mathrm{Bu}$ çalışmalar, optimizasyon problemi ve optimizasyon yöntemine göre Çizelge 1'de özetlenmiştir.

Literatüre bakıldığında kuru tip transformatörler için birçok sezgisel optimizasyon yöntemi kullanıldığı görülmektedir. $\mathrm{Bu}$ yöntemler incelendiğinde en büyük dezavantajın algoritmalarının yerel en iyi sonuca takılıp global en iyiyi bulamamasıdır. Ateş böceği algoritması, çalışma yapısından dolayı global en iyiyi bulmaya çalışmaktadır. Literatürde yeni kullanılmaya başlanan ve performans analizi diğer algoritmalara kıyasla çok daha yüksek olan ateş böceği algoritmas1 kuru tip güç transformatörünün verimlilik hesaplamasında ilk defa bu çalışmada kullanılacaktır. Yeni bir sezgisel yaklaşım olan ateş böceği algoritması kullanılarak en optimum tasarım boyutu belirlenmiștir. Bu yapılan çalıșma, transformatör üreticileri için maksimum verim ile birlikte optimum ağırlık ve maliyet açısından yararlılık sağlayacaktır. 
Çizelge 1. Kuru tip transformatörlerin optimizasyonu

\begin{tabular}{|c|c|}
\hline $\begin{array}{l}\text { Optimizasyon } \\
\text { problemi/Uygulama alanı }\end{array}$ & $\begin{array}{l}\text { Optimizasyon } \\
\text { yöntemi }\end{array}$ \\
\hline $\begin{array}{l}\text { Kuru tip } \\
\text { transformatörlerin sarg1 } \\
\text { s1caklığ1 analizi [1] }\end{array}$ & Yapay Zeka \\
\hline $\begin{array}{l}\text { Kuru tip transformatörün } \\
\text { maliyet optimizasyonu } \\
\text { [3] }\end{array}$ & Genetik algoritma \\
\hline $\begin{array}{l}\text { Kuru tip transformatörün } \\
\text { ağırlık optimizasyonu [5] }\end{array}$ & $\begin{array}{l}\text { Tabu arama } \\
\text { algoritması }\end{array}$ \\
\hline $\begin{array}{l}\text { Kuru tip } \\
\text { transformatörlerde bobin } \\
\text { ve soğutma kanallarının } \\
\text { şekil optimizasyonu [6] }\end{array}$ & $\begin{array}{l}\text { Hesaplamalı } \\
\text { akışkanlar dinamiği } \\
\text { ve genetik } \\
\text { algoritma }\end{array}$ \\
\hline $\begin{array}{l}\text { Bir elektrik } \\
\text { transformatörünün } \\
\text { mutlak bobin } \\
\text { konfigürasyonu etkin } \\
\text { soğutması için 3-boyutlu } \\
\text { optimizasyonu [7] }\end{array}$ & $\begin{array}{l}\text { Hesaplamalı } \\
\text { akışkanlar dinamiği } \\
\text { - genetik algoritma } \\
\text { (CFD-GA) }\end{array}$ \\
\hline $\begin{array}{l}\text { Farklı yüklenme } \\
\text { durumlarında } \\
\text { transformatörün verim } \\
\text { optimizasyonu [8] }\end{array}$ & $\begin{array}{l}\text { Yerçekimsel arama } \\
\text { algoritması }\end{array}$ \\
\hline $\begin{array}{l}\text { Çok yüksek verimli } \\
\text { dağıtım transformatörleri } \\
\text { [9] }\end{array}$ & Yapay Zeka \\
\hline $\begin{array}{l}\text { Kuru tip transformatör } \\
\text { sarg1 termal analizi [10] }\end{array}$ & $\begin{array}{l}\text { Farklı sinir ăg } 1 \\
\text { yöntemleri }\end{array}$ \\
\hline $\begin{array}{l}\text { Kuru tip } \\
\text { transformatörlerin } \\
\text { gelişimini destekleyen } \\
\text { elektromanyetik } \\
\text { simülasyonlar [11] }\end{array}$ & Yapay Zeka \\
\hline $\begin{array}{l}\text { Kuru tip transformatör } \\
\text { optimizasyonu [12] }\end{array}$ & $\begin{array}{l}\text { Yüksek performans } \\
\text { bulut hesaplama } \\
\text { performans } \\
\text { değerlendirmesi }\end{array}$ \\
\hline $\begin{array}{l}\text { Kuru tip } \\
\text { transformatörlerde hata } \\
\text { teşhisi [13] }\end{array}$ & $\begin{array}{l}\text { Geliştirilmiş yapay } \\
\text { balık sürüsü } \\
\text { algoritması }\end{array}$ \\
\hline
\end{tabular}

\section{KURU TIP TRANSFÖRMATÖRÜN MODELEMESI}

$\mathrm{Bu}$ bölümde ayrıntılı olarak üç faz kuru tip transformatörün ayrıntılı matematiksel analizi verilecektir.

$S=\sqrt{3} \times U \times I$

Eşitlik 1'de $\mathrm{S}$ görünür gücü, $\mathrm{U}$ birincil veya ikincil sarg1 gerilimini, I ise birincil veya ikincil sargılarından geçen akımı ifade eder.

$S_{2}=\sqrt{3} \times U_{2} \times I_{2}$

İkincil sargılarındaki görünür güç Eşitlik 2'deki gibi elde edilir.

$S_{1}=\sqrt{3} \times U_{1} \times I_{1}$

Birincil sargılarındaki görünür güç Eşitlik 3'deki gibi elde edilir.

$q f e=C \times \sqrt{\frac{1000 \times S}{3 \times f}}$

Eşitlik 4'de qfe, çekirdek demir kesitini, C, transformatör demir kesiti uygunluğudur. Kuru tip transformatörler için 5,9 ile 10,6 arasında değişmektedir [14].

$D=2 \times \sqrt{\frac{q f e}{0,677 \times \pi}}$

Eşitlik 5 ile transformatör nüve çekirdeğini çevreleyen dairenin çapı hesaplanır. Burada D çapı ifade eder [14]

$$
\begin{aligned}
& w_{1}=\frac{U_{1}}{\sqrt{3} \times 4,44 \times f \times \phi \times 10^{-8}} \\
& w_{2}=\frac{U_{2}}{\sqrt{3} \times 4,44 \times f \times \phi \times 10^{-8}}
\end{aligned}
$$


Eşitlik 6 ve 7'de her bir bacak için gerekli olan sarım sayısı bulunur. $\phi$ çekirdek kesitinden geçen toplam manyetik akıyı ifade eder [14].

$$
\begin{aligned}
& q_{1}=\frac{I_{1}}{s} \\
& q_{2}=\frac{I_{2}}{s}
\end{aligned}
$$

Eşitlik 8 ve 9'da $\mathrm{q}_{1}, \mathrm{q}_{2}$ transformatörün birincil ve ikincil sarg1 kesitlerini, s ise akım yoğunluğunu ifade eden bir değer olup kuru tip transformatörler için 1,7 ile 2 arasında değişmektedir [14].

$$
L_{S}=\frac{2 \times w_{1} \times I_{1}}{A_{S}}
$$

Eşitlik 10'da $\mathrm{L}_{\mathrm{s}}$ primer ve sekonder $\operatorname{sarg}_{1}$ yükseklini ifade eder. Burada $\mathrm{A}_{\mathrm{s}}$ özgül amper sarımdır Şekil 1'den elde edilir.

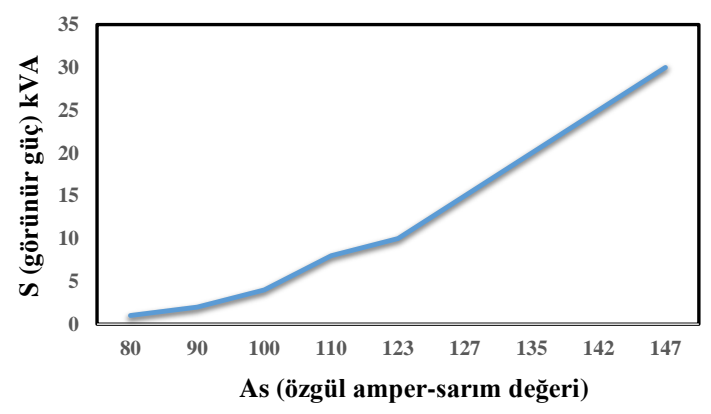

Şekil 1. Kuru trafolarda özgül amper-sarıma ilişkin karakteristik eğrisi

$$
a=4 \times \frac{w_{2} \times q_{2}}{\left(100 \times k_{c u} \times L_{S}\right)}
$$

Eşitlik 11'de a ifadesi, çekirdek tipi transformatör için pencere genişliğidir. Burada $\mathrm{k}_{\mathrm{cu}}$ pencere bakır doldurma faktörüdür.

$$
\begin{aligned}
& L m_{1}=\pi \times(D+3.32) \\
& L m_{2}=10^{-2} \times \pi \times\left(10 \times D+8+a_{2}\right)
\end{aligned}
$$

Eşitlik 12 ve 13'ü kullanılarak ortalama sarg1 uzunlukları elde edilir.

Transformatörün her üç bacağ 1 için birincil bakır ağırlığ 1 Eşitlik 14'de belirtilmiştir.

$$
G c u_{1}=3 \times \gamma_{c u} \times w_{1} \times q_{1} \times L m_{1} \times 10^{-5}
$$

İkincil sargının bakır ağırlığı ise Eşitlik $15^{\prime}$ de belirtilmiştir.

$$
G c u_{2}=3 \times \gamma_{c u} \times w_{2} \times q_{2} \times L m_{2} \times 10^{-3}
$$

$\mathrm{Bu}$ eşitliklerde yer alan $\gamma_{\mathrm{cu}}$, bakır özgül ağırlığıdır ve $75^{\circ} \mathrm{C}^{\prime}$ lik sıcaklık derecesinde 8,9 değerini alır [14].

$$
\begin{aligned}
& r_{1}=\rho \frac{L m_{1} \times w_{1}}{q_{1}} \\
& r_{2}=\rho \frac{L m_{2} \times w_{2}}{q_{2}}
\end{aligned}
$$

Bakır sarg1 direncini elde edilirken de kullanılan $\rho=0,0216 \mathrm{~mm} / \mathrm{m}$ alınmıştır. Bakır kayıplarını hesaplamak için Eşitlik 16 ve Eşitlik 17 kullanılır.

$$
\begin{aligned}
& P c u_{1}=3 \times I_{1}^{2} \times r_{1} \\
& P c u_{2}=3 \times I_{2}^{2} \times r_{2} \times k
\end{aligned}
$$

Eşitlik 18 ve 19'dan bulunan değerler toplanarak Eşitlik 20'deki transformatördeki toplam bakır kaybı elde edilir [14].

$$
P c u=P c u_{1}+P c u_{2}
$$

Transformatördeki diğer kayıp güç ise demir nüve üzerinden meydana gelmektedir. Demir kayıplarını elde etmek için demir ağırlığının hesaplanması gerekmektedir. Demir ağırlığı transformatörün boyunduruk ve bacak ağırlığı olarak ifade edilir.

$$
G f e_{b}=3 \times \gamma f e \times q f e \times L_{S} \times 10^{-4}
$$


Eşitlik 21'deki Gfe transformatör üç adet bacağının ağırlığıdır. Bu değer Eşitlik 22'de yerine koyulursa her üç bacağın demir kaybı elde edilmiş olur.

$$
P f e_{b}=G f e_{b} \times p f e_{b}
$$

Eşitlik 21'de yer alan $\gamma$ fe, demir özgül ağırlığı olup 7,6 değerini alır. Gfe $\mathrm{b}_{\mathrm{b}}$ ise transformatör bacak ağırlığıdır. Diğer ağırlık ise transformatör boyunduruk ağırlığıdır. G $\mathrm{fej}_{\mathrm{fej}}$ olarak Eşitlik 23'de ifade edilmiştir [14].

$$
G_{f e j}=6 \times 10^{-3} \times \gamma f e \times q_{f e j} \times(2 \times M+0.8 \times D)
$$

Eşitlik 23'de a pencere genişliği, $\mathrm{L}_{\mathrm{s}}$ transformatör pencere yüksekliğini ifade eder.

$$
p_{f e j}=\varepsilon_{2} \times p_{10} \times\left(\frac{B_{j}}{10000}\right)^{2}
$$

Eşitlik 24'deki pej özgül boyuduruk demir kayb1, $\varepsilon_{2}$ ilave kayıp faktörü, $B_{j}$ boyunduruk bacak endüksiyonudur.

$$
P_{f e j}=G_{f e j} \times p_{f e j}
$$

Eşitlik 21 ve Eşitlik 23 toplandığında Eşitlik 26'daki transformatör demir ağırlığı elde edilmiş olur.

$$
G f e=G f e_{b} \times G f e j
$$

Eşitlik 27 ile watt cinsinden transformatör demir kaybı elde edilir.

$$
P_{\text {Fekaylp }}=P_{f e b} \times P_{f e j}
$$

Transformatörün toplam ağırlı̆̆ı, birincil sarg1 ağırlığının, ikincil sargı ağırlığının, boyunduruk ağırlığı ile bacak ağırlığının toplamına eşittir ve Eşitlik 28'de verilmiştir.

$$
G_{\text {toplam }}=G c u_{1}+G c u_{2}+G f e_{b}+G f e_{j}
$$

Transformatördeki toplam kayıp, bakır kaybı ve demir kaybının toplanmasıyla Eşitlik 29'daki gibidir:

$$
P_{\text {kayp }}=P_{c u} \times P_{\text {Fekayp }}
$$

Transformatörün verimi ise yüzde olarak transformatörden alınan gücün transformatöre verilen güce oranlanması ile Eşitlik 30'da ifade edilmiştir.

Verim $=\frac{\left(100 \times S_{2}\right)}{S_{2}+P_{c u}+P_{f e}}$

Transformatörün veriminin \% 90 ile \% 99 arasında olması transformatörün tasarım ve kullanım yönünden doğru seçim olduğunu gösterir.

\section{MATERYAL VE METOT}

Ateş böceği algoritması, ateş böceklerinin toplumsal davranışlarından etkilenerek geliştirilmiş bir sezgisel optimizasyon yöntemidir [15]. Ateş böceklerinin birbirleriyle haberleşirken yaptıkları yanıp sönme hareketlerinin formüle edilmesiyle bu optimizasyon yöntemi geliştirilmiştir.

Yakın zamanda yapılan çalışmalar bu algoritmanın diğer geleneksel yöntemlere göre daha etkili ve verimli sonuçlar verdiğini göstermektedir. Algoritmanın çalışma esnasında rastgele üretilen sayılar kullanması ve iterasyonlar boyunca ateş böcekleri arasında global iletişim kurması, tek boyutlu problemlerin yanı sıra çok boyutlu optimizasyon problemlerinde dahi başarılı bir şekilde uygulanmasını sağlamaktadır.

Ateş böceği algoritmasının çalışma mantığında üç önemli kural vardır: Birincisi, tüm ateş böcekleri cinsiyetsiz olarak kabul edilir ve cinsiyetlerine bakılmaksızın daha çekici ve daha parlak olana doğru hareket edilir. İkincisi, bir ateş böceğinin çekiciliği, havanın ışığı emmesi nedeniyle diğer ateş böceğinden uzaklaştıkça azaldığı için parlaklığıyla orantılıdır. Üçüncüsü, bir ateş böceğinin parlaklığı veya 1şığı yoğunluğu belirli 
bir sorunun amaç fonksiyonunun değeri tarafindan belirlenir. Maksimizasyon problemleri için, 1 șı yoğunluğu uygunluk fonksiyonun değeri ile orantılıdır. Ateş böceği algoritmasının akış diyagramı Şekil 2'de gösterilmiștir.

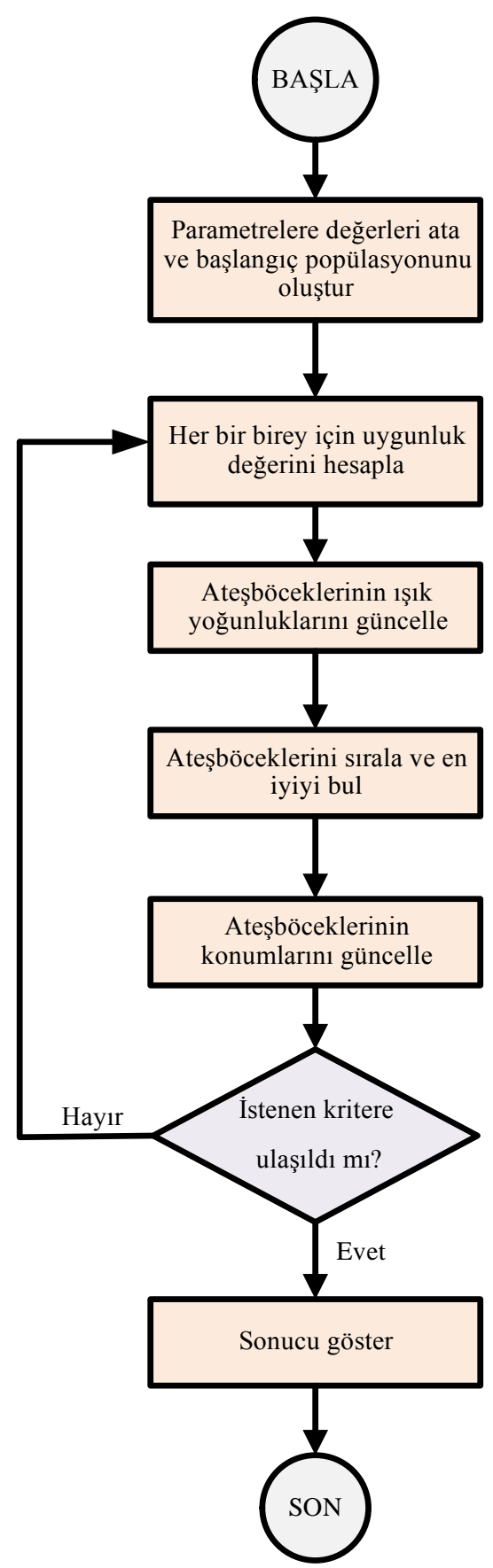

Şekil 2. Ateş böceği algoritmasııın akış diyagramı 


\section{ANALİZ VE SONUÇLAR}

Bu çalışmada 100 kVA'lık kuru tip transformatör için verimin maksimum olduğu şekilde trafo tasarımı amaçlanmıştır. Uygunluk fonksiyonu olarak verim değeri kullanılmış ve verimi maksimize edecek şekilde parametreler güncellenmiştir.

Çizelge 2. Ateş böceği algoritması yöntemiyle elde edilen sonuçlar

\begin{tabular}{|c|c|c|c|}
\hline Değişken & Sembol & Birim & Değer \\
\hline $\begin{array}{l}\text { Demir kesiti uygunluk } \\
\text { faktörü }\end{array}$ & $\mathrm{C}$ & $\mathrm{cm}^{2} *$ joule $^{-1 / 2}$ & 5,93 \\
\hline $\begin{array}{l}\text { Sargılardaki akım } \\
\text { yoğunluğu }\end{array}$ & S & $\mathrm{A} / \mathrm{mm}^{2}$ & 2,4185 \\
\hline Pencere genişliği & $\mathrm{a}$ & $\mathrm{cm}$ & 17,6860 \\
\hline Demir çekirdeğin çapı & $\mathrm{D}$ & $\mathrm{cm}^{2}$ & 16,9694 \\
\hline $\begin{array}{l}\text { Birincil sarg1 } \\
\text { uzunluğu }\end{array}$ & Lm1 & $\mathrm{cm}$ & 63,7409 \\
\hline İkincil sargı uzunluğu & $\mathrm{Lm} 2$ & $\mathrm{~cm}$ & 55,8241 \\
\hline Demir kesiti & qfe & $\mathrm{cm}^{2}$ & 153,1119 \\
\hline $\begin{array}{l}\text { Trafo toplam demir } \\
\text { kayb1 }\end{array}$ & $P_{\text {fekayip }}$ & Watt & 0,8723 \\
\hline $\begin{array}{l}\text { Trafo toplam bakır } \\
\text { kaybı }\end{array}$ & $\mathrm{P}_{\mathrm{cu}}$ & Watt & 2,0949 \\
\hline Verim & & & 0,9712 \\
\hline
\end{tabular}

Çalışmada optimum değerleri elde edilmek istenen parametreler akım yoğunluğu ve kesit uygunluk faktörüdür. Akım yoğunluğunun 2,2 ile $3,5 \mathrm{~A} / \mathrm{cm}^{2}$ sınırlarında ve kesit uygunluk faktörünün 5,9 ile 10,6 sınırlarında olması ayarlanmıştır.

Algoritma çalışırken bazı şartlarında sağlanması gerekmektedir. Trafodan elde edilen verimin $\% 90$ ile \%99 değeriler arasında olması istenmektedir. Ayrıca, çalışmada amaçlanan trafo çekirdek tipi trafo olduğu için pencere yüksekliği ile pencere genişliği arasındaki oranın (Ls/a) 2,0 ile 4,5 olması gerektiği kriter olarak belirlenmiştir.

100 kVA'lık kuru tip transformatör için verimini maksimize edecek şekilde sezgisel bir yöntem olan ateş böceği algoritması kullanılarak yapılan transformatör tasarımından elde edilen sonuçlar
Çizelge 2'de verilmiştir. Amaç fonksiyonunun iterasyona bağlı olarak değişimini gösteren grafik Şekil 3'deki verim-iterasyon grafiğinde gösterilmiştir.

\section{TARTIŞMA VE GELECEK ÇALIŞMALAR}

$\mathrm{Bu}$ çalışma sayesinde kuru tip transformatör için verimlilik maksimum seviyede olacak şekilde transformatör tasarımı yapılmıştır. Bir sonraki çalışmada diğer transformatör tiplerinde de bu algoritma uygulanarak en efektif çözümler sunulacaktır. $\mathrm{Bu}$ sayede her tip transformatör üreticileri için verim maksimum seviyeye çekilerek ağırlık ve maliyet açısından da optimum tasarım sağlayacaktır. 


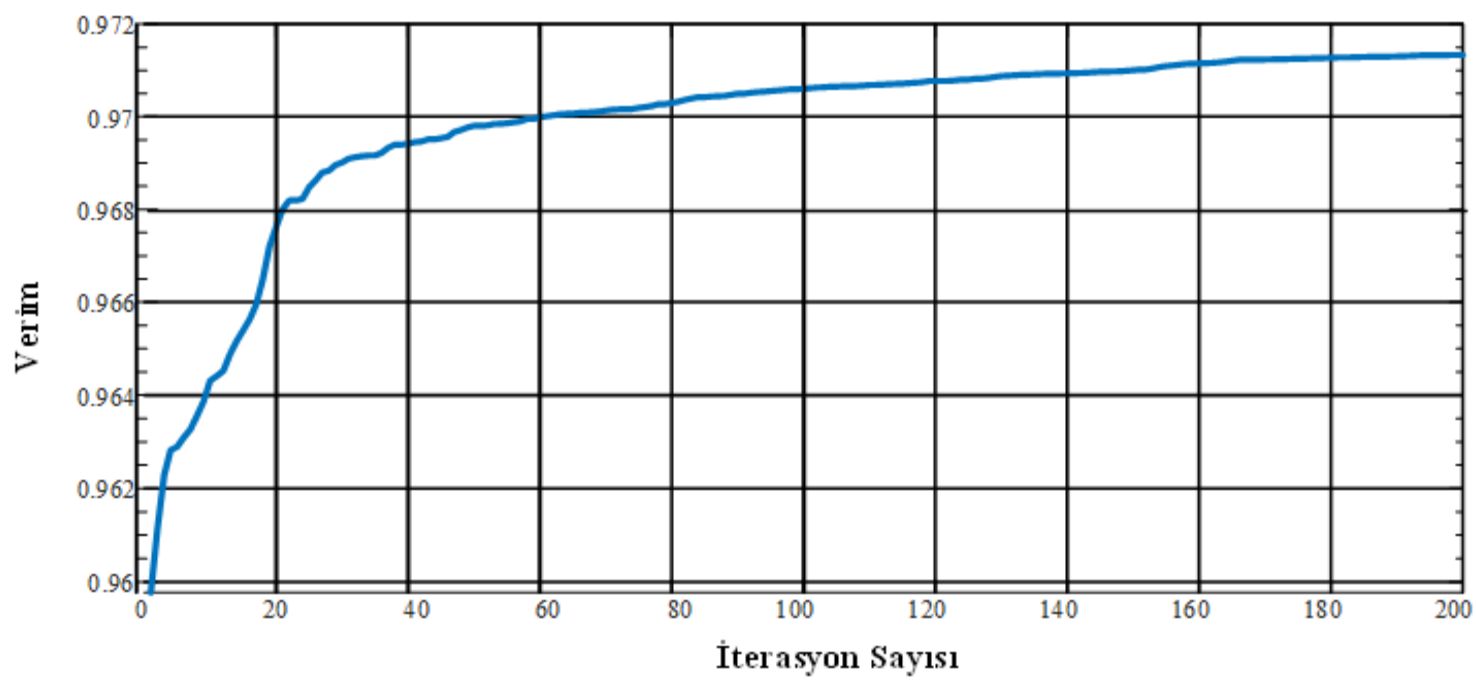

Şekil 3. Trafodaki verimin iterasyon sayısına bağlı değişimi

\section{KAYNAKLAR}

1. Finocchio, M.A.F., Lopes, J.J., França, J.A., Piai, J. C., Mangili, J. F., 2017. Neural Networks Applied to the Design of Dry-type Transformers: An Example to Analyze the Winding Temperature and Elevate the Thermal Quality. International Transactions on Electrical Energy Systems, 27(3).

2. Berrogain, M., Carlen, M., 2013. Dry-type transformers for subtransmission. $22^{\text {nd }}$ International Conference and Exhibition on Electricity Distribution (CIRED 2013).

3. Çelebi, M., 2008. Genetik Algoritma ile Kuru bir Trafonun Maliyet Optimizasyonu, ELECO, 189-193.

4. Gezegin, C., Dirik, H., Ergül, E.U., Özdemir M., 2016. Kuru Tip Trafoların Ortalama ve En Yüksek Sargı Sicaklık Artışlarının İncelenmesi. İleri Teknoloji Bilimleri Dergisi, $5(1)$.

5. Tosun, S., Öztürk, A., Demir, H., Kuru, L., 2012. Kuru Tip Transformatörün Tabu Arama Algoritması Yöntemi ile Ağırlık Optimizasyonu, İleri Teknoloji Bilimleri Dergisi, 1(1), 17-26.

6. Smolka, J., Nowak, A.J., 2011. Shape Optimization of Coils and Cooling Ducts in Dry-type Transformers using Computational
Fluid Dynamics and Genetic Algorithm, IEEE Transactions on Magnetics, 47(6), 1726-1731.

7. Smolka, J., 2013. CFD-based 3-D Optimization of the Mutual Coil Configuration for the Effective Cooling of an Electrical Transformer, Applied Thermal Engineering, 50(1), 124-133.

8. Alcan, Y., Öztürk, A., Özmen, Ö., 2014. Yerçekimsel Arama Algoritması ile Değişik Çalışma Koşulları için Transformatör Verim Optimizasyonu, ISITES, Karabük.

9. Carlen, M., Xu, D., Clausen, J., Nunn, T., Ramanan, VR., Getson, D.M., 2010. Ultra High Efficiency Distribution Transformers, IEEE PES T\&D 2010, New Orleans, LA, 1-7.

10. Aşkın, D., İskender, İ., Mamizadeh, A., 2011. Farklı Yapay Sinir Ağları Yöntemlerini Kullanarak Kuru Tip Transformatör Sargısının Termal Analizi, Gazi Üniversitesi Mühendislik-Mimarlık Fakültesi Dergisi, 26(4), 905-913.

11. Murillo, R., Smajic, J., Tepper, J., Nogués, A., Steinmetz, T., 2012. Electromagnetic Simulations Supporting the Development of Dry-Type Transformers for Subtransmission Voltage Levels, CIGRE Paris Session, A2-208.

12. Wu, W., Gentzsch, W., Kern, J.A., 2016. DryType Transformer Optimization using High Performance Cloud Computing: Performance Evaluation, SoutheastCon, Norfolk, VA, 1-2. 
13.Zhang, M., Wang, N., Ding, X., 2013. Improved Artificial Fish Swarm Algorithm for Fault Diagnosis of Dry-Type Transformer, Fourth International Conference on Digital Manufacturing \& Automation, Qingdao, 679-683.

14. Boduroğlu, T., 1988. Elektrik Makineleri Dersleri Cilt 1, Transformatörler, Beta Basım, İstanbul.

15. Yang, X.S., 2009. Firefly Algorithms for Multimodal Optimization. Stochastic Algorithms: Foundations and Applications, SAGA 2009, Lecture Notes in Computer Science, 5792. Berlin: Springer Verlag, 169-178. 
